\title{
Health Informatics for Development: a Three- pronged Strategy of Partnerships, Standards, and Mobile Health
}

\section{Contribution of the IMIA Working Group on Health Informatics for Development}

\author{
A. Marcelo', A. Adejumo², D. Luna ${ }^{3}$ \\ ${ }^{1}$ IMIA Health Informatics for Development Working Group Chair, National Telehealth Center, \\ University of the Philippines Manila, Philippines \\ ${ }^{2}$ Health Information Systems Programme, Nigeria \\ ${ }^{3}$ IMIA Health Informatics for Development Working Group Co-Chair, Hospital Italiano, Buenos Aires, Argentina
}

\begin{abstract}
Summary
Objective: Describe the issues surrounding health informatics in developing countries and the challenges faced by practitioners in building internal capacity. From these issues, the authors propose cost-effective strategies that can fast track health informatics development in these low to medium income countries (LMICS). Methods: The authors conducted a review of literature and consulted key opinion leaders who have experience with health informatics implementations around the world.

Results: Despite geographic and cultural differences, many LMICS share similar challenges and opportunities in developing health informatics.

Conclusions: Partnerships, standards, and inter-operability are well known components of successful informatics programs. Establishing partnerships can be comprised of formal inter-institutional collaborations on training and research, collaborative open source software development, and effective use of social networking. Lacking legacy systems, LMICs can discuss standards and inter-operability more openly and have greater potential for success. Lastly, since cell phones are pervasive in developing countries, they can be leveraged as access points for delivering and documenting health senvices in remote under-served areas. Mobile health or $\mathrm{mHealth}$ gives LMICs a unique opportunity to leapfrog through most issues that have plagued health informatics in developed countries. By employing this proposed roadmap, LMICS can now develop capacity for health informatics using appropriate and cost-effective technologies.
\end{abstract}

Keywords

eHealth, mHealth, mobile, partnerships, information systems

Yearb Med Inform 2011:96-101

\section{Introduction}

Hersh [1] defines informatics as the "discipline focused on the acquisition, storage, and use of information in a specific setting or domain", If applied to health, he employs the term "biomedical and health informatics (BMHI)" and further qualifies it as the "optimal use of information, often aided by the use of technology, to improve individual health, health care, public health, and biomedical research".

"Health informatics for development" is a working group of the International Medical Informatics Association dedicated to investigating how health informatics capability can be built in lowto-medium income countries (LMICs), and conversely, how health informatics can contribute to the their development. Hersh's definition resonates completely with the health informatics found in developing countries although social, political and economic issues manifest more prominently in these countries [2].

\section{Objectives}

Define the sub-domain of "health informatics for development" and recommend a roadmap that developing countries can take to fast track its uptake in their local context.

\section{Methodology}

Two methods were chosen for this paper. One is through literature review and the other is through a survey with key opinion leaders and practitioners.

Literature search in Pubmed for the term "health informatics for development" yielded no matches. An alternative search using Medical Subject Headings for "health informatics" combined with "development" revealed seventynine articles of which two were excluded for irrelevance. Among the seventy-seven articles, the most recurring themes were "public health", "surveillance", "geographic information systems", "health information systems", and "open source". Only nine articles were about countries in the Africa or Asia.

For the second method, key opinion leaders and practitioners in developing countries were consulted. They were asked to provide a brief situational analysis from their respective regions, to show examples of current state-of-the art and to list predominant issues that hinder them from experiencing the full benefits of health informatics in their regions.

\section{Latin America}

The development of health informatics has mixed results in Latin America. Although its contribution to better 
health care has been recognized, there are in fact only a few initiatives at national scale in this region. These could be attributed to the low priority placed in health information management by ministries of health. This explains why majority of the advances have been made by the private sector creating a huge divide that exacerbates the disparity to access to such technologies. Most health informatics research therefore come from private institutions with minimal involvement by government.

Training initiatives in medical informatics, though existent, is progressing at a slow pace. Beyond education programs generated from Argentina [3], Brazil [4], and Uruguay [5], there are few other projects of this type in the rest of Latin America. The inclusion of informatics as a subject in medical schools is an important activity towards creating a competent workforce. Recently, several universities in Latin America have started offering postgraduate programs in health informatics.

By far the largest improvements have been in standards development with Brazil[6] demonstrating its strength through the formal adoption by the Ministry of Health. Countries like Chile [7] followed soon after but the rest of the region has not responded as quickly. Furthermore, and perhaps related to the contribution of private enterprises, is that most developments in health informatics are proprietary software, and very few are open source.

In conclusion, there are now beginning interests in informatics initiatives and state policies from several countries in the region, but the majority remains private contribution.

\section{Africa}

Health informatics development in Africa has seen a gradual rise in the field over the last decade. This is due to the growing interest in the use of information and communications technology (ICT), a phenomenon largely absent for the most part of the last decade.
Still Africa lags behind due to the relatively low penetration of ICT use in many African countries especially sub-Saharan Africa. Unstable electric power supply in many parts of Africa has made the use of computers and other devices in health care an expensive and resource-consuming venture relegating health informatics projects to small donor-driven interventions rather to the larger national systems.

Mobile phones, on the other hand, have had tremendous success in Africa in the last 5 years and the region is one of the largest growing markets in the world. The low cost and minimal energy requirements of mobile phones has opened new vistas for health informatics for development.

The advent of open source technology in Africa has helped bridge the software gap in the continent. The growing use of open source software packages specially the District Health Information System (www.DHIS2.org) and OpenMRS (www.openmrs.org) is shaping the landscape of electronic data systems. Packages like DHIS have been adopted as national templates for health data management. The bias towards open source software was initially due to the large costs incurred with proprietary systems, but recently, the benefits of full source code access and control are increasingly being recognized.

\section{Asia}

The progress of health informatics in Asia can be viewed as straddling between that of progressive Latin America and of up-and-coming Africa. Several factors have made health informatics development challenging in this region. First is that it is composed of several archipelagos (Philippines, Indonesia, Malaysia, etc) making travel and networking difficult and expensive. Second, unlike Latin America, there is no common language that connects all countries in the region. Discussions become tedious and semantics are lost in translation despite the use of electronic means of communications. Last but not the least, there are limited investments in building capacity for health informatics in the region.

Similar to Latin America, governments have been slow in adopting health informatics standards despite the strong recommendations of experts including the World Health Organization [WHO]. Although available, health informatics leaders in the region have not interacted more closely.

All three regions share, to some extent, social, political and economic challenges for their constituencies that distinguishes their attempts at developing health informatics within their countries from those in developed ones.

\section{The Context for Health Informatics Development in the Developing Regions}

Health informatics is a mature and well-recognized discipline in first world countries. This could be attributed to the ready availability of technology infrastructure that permits the in-depth study of the many facets of the field. Since hardware, software, and fast networks are available in these countries, they are naturally able to investigate the various nuances of health information management. These conditions are not readily available in developing countries. Conventional hardware such as servers and workstations are impractical in remote underserved areas plagued with power fluctuations. Lacking the necessary technology infrastructure therefore, health informatics capacity becomes limited and expertise development stymied. Without the enabling technology environment, the necessary human resources to support health informatics cannot be developed. Further, without the manpower, the field of health informatics cannot be nurtured hindering development of formal training pro- 
grams. This creates the vicious cycle that sets back health informatics development in LMICs.

In the area of software development, use of proprietary software limits the ability of local programmers to observe the full spectrum of software engineering practices. Licensing serve as barriers to adoption and often become reasons for inability to innovate and to experiment with new software development techniques.

In many instances, countries that are just beginning with health informatics do not have privacy frameworks that can provide consumer confidence with computerized health information systems. This prevents health professionals from trusting these new electronic systems and from creating a supportive ecosystem.

One of the most important components of successful health information systems is the adoption of standards. But due to the lack of local experts, LMICs are unable to leverage these standards even if they are available for free. Without these standards, noninteroperable systems become the norm and inter-operability becomes an almost impossible goal.

\section{Health Informatics for Development: a Three- pronged Strategy}

Recognizing the unique problems of LMICs, the HI4Dev Working Group proposes a three-pronged strategy to facilitate development of health informatics in these challenging situations. These three are partnerships, inter-operability, and mobile health.

\section{Strategy 1: Establish Partnerships}

Given the vicious cycle of the technology infrastructure challenges and human resource deficiencies in developing countries, it is important for interventions in these areas to be implemented at the right time and in the right sequence. Building a sophisticated technology infrastructure without the capable manpower is not costeffective. On the other hand, developing professionals in health informatics without the appropriate technology environment may lead to frustrations and subsequent migration.

An affordable and practical way to break this cycle is to establish collaborations with first world institutions that already have a wealth of knowledge in the domain of health informatics. This partnership fast-tracks the input of fundamentals to quickly bring the local human resource up to speed with the theories required for successful implementations.

These principles however should be introduced through practical implementations in local settings that provide the environment to test and validate these theories. It is a well known fact that principles established in developed countries are not always transplantable to developing ones. Creating an collaborative implementation laboratory brings together theory and practice thereby exposing strengths and weaknesses in the prevailing frameworks.

A partnership could be a formal agreement between a local university and a foreign one to conduct training and research in health informatics in the developing country setting. This creates a mutually beneficial relationship to both schools: for the former to rapidly gain access to principles and to the experts who wrote them, and for the latter to allow their theories access to real world informatics implementations, an opportunity becoming increasingly rare in the developed world.

There are several examples of these partnerships coming to fruition. There is the Health Informatics Building Blocks (HIBBs), the Global Health Informatics Partnership (GHIP), PAN Asian Collaboration for Evidence-based e-Health Adoption and Application
(PANaCeA), Réseau en Afrique Francophone pour la Télémédecine (RAFT), INDEHELA, and AMAUTA.

The Health Informatics Building Blocks The Health Informatics Building Blocks or HIBBs is a program developed by the American Medical Informatics Association in which:

"...distance-learning supports clinical and health informatics training in low-resource countries where greater understanding and use of informatics and databases can enable better support of community care and public health services. This education initiative will provide an infrastructure that enables a broad audience such as community health workers in developing countries to acquire skills and knowledge in informatics at little or no cost to indigenous institutions or individuals." [8].

Last February 2010, AMIA received support from the Rockefeller Foundation to implement HIBBs in sub-Saharan Africa [9]. The target recipients of the program will be primary care providers, technical staff and health policy-makers.

Global Health Informatics Partnerships The American Medical Informatics Association (AMIA) created the Global Health Informatics Partnerships (GHIP) with a vision of "creating innovative collaborations for transforming information into better health for all." GHIP aims to "improve health care delivery world wide by establishing and supporting an international collaborative learning community focused on the use of health care information." GHIP is a partnership of partnerships with networks of health informatics advocates contributing to the promotion of health information management to societies. It has strong focus on creating solutions that are "locally relevant and locally owned." GHIP could provide a venue to promote the partnership prong in the developing world. 


\section{PANACEA}

The International Development Research Centre of Canada (IDRC) together with the Aga Khan University initiated the PAN Asian Collaboration for Evidence-based e-Health Adoption and Application (PANACeA) [10]. The project started in February 2007 with the goal of generating evidence in the field of eHealth within the Asian context bringing together researchers from all over Asia. Eight eHealth projects were funded "to generate evidence for the adoption of technologically, economically and socio-culturally sound eHealth applications in multiple countries." The eight PANACeA projects are shown in the table.

PANACeA was able to gather experts in the region and provide them with an environment for exchanging ideas and expertise in eHealth who, themselves, collaborated using readily available tools.

Réseau en Afrique Francophone pour la Télémédecine or RAFT [11] has webcasting of interactive courses as its core activity while INDEHELA [12] (Informatics Development for Health in Africa) is a long-term research programme that started as research partnership between the University of Kuopio, Finland, and the Obafemi Awolowo University, Nigeria, in 1989. The AMAUTA Global Training in Health Informatics program [13] was developed "to train Peruvian healthcare professionals in the application of informatics to health". This collaborative program is an institutional partnership between Universidad Peruana Cayetano Heredia (UPCH), Universidad Nacional Mayor de San Marcos, and the University of Washington (UW), Seattle, Washington, USA, with the support of the Fogarty International Center (FIC)/ National Institutes of Health (NIH).

Summing it up, in the true spirit of global health, these examples of collaborations are able to meld best practice and lessons learned and employ them in resource-constrained settings that can directly address the health needs of their citizens.

Table 1 Projects funded by PANACeA

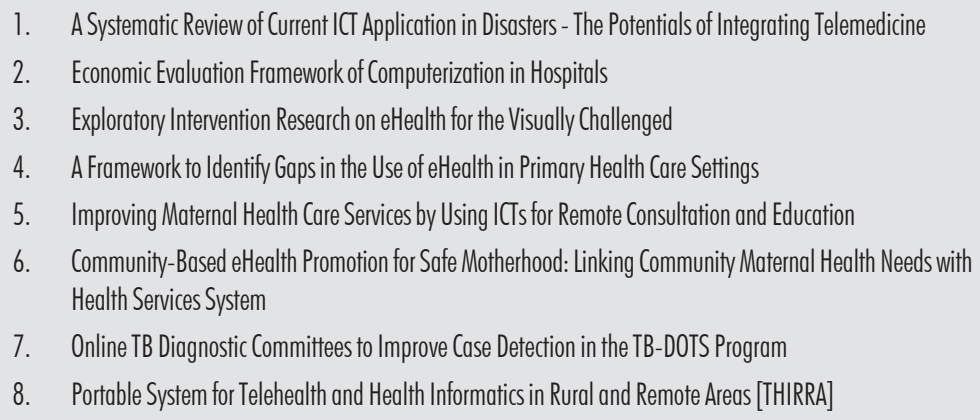

\section{Table 2 Examples of Social Networks in the Internet}

MySpace: Usually used for cultural purposes, offers a website that can be customized with videos, photos, a blog and a whole series of different and varied applications.

Facebook: It began as a college social network, but has become the largest network in the world. It is currently the network with more registered users and their goals are mostly entertainment.

Flickr: A photo-sharing network and amateur photographers.

Skype: Not just a social network, but a phone and messaging service that is widely used worldwide.

Twitter: A free service that allows users to send micro-entries or text-based short messages, called „tweets" that can be performed either by the Twitter website, or via a mobile phone.

Linkedln: Social network for professionals.

\section{Partnerships to Collaborate on Software Development using Free and Open Source Software}

A significant gap in health informatics is the availability of a local group of people who can technically support the needs of their health professionals. This limitation is brought upon by a complex set of factors that range from lack of access to hardware to expensive licensing fees for software development. These obstacles prevent local manpower from controlling their projects keeping them dependent on proprietary entities whose interests may not be completely aligned with their own.

Free and open source software (FOSS) is a well known phenomenon in software engineering that contributes to technical and organizational capacity in health informatics. The IMIA has considered FOSS to be significant enough that it created the Open Source Working Group (please refer to this yearbook's article on the OSWG). The opportunities with FOSS are endless and suffice it to say that it is an integral component of the health informatics for development roadmap because of the unprecedented liberties it gives to developers to create their own applications that can transform their health systems.

\section{Partnerships through Social Networking}

Social networks have become a truly significant new phenomenon in human communication and have a profound impact on the way that people communicate and connect with each other. In the social sciences, a social network is an organization of people who relate to each other tightly or loosely. 
On the Internet, social networks are web-based services that allow people who share certain profiles (such as professional background, entertainment preferences, advocacies, or networks of patients) to communicate their experiences and knowledge. These services promote interactions among people, known or unknown to each other, but who share something in common.

Recent advances in technology have made it possible to easily access and use social networks. Investments in usability allow many with limited instruction or training to access a network site. This has made social networks on the Internet very viable communication and collaboration tools for health informatics.

By employing social networks, health informatics for development can:

- encourage participation and collaborative work between people, allowing users to participate in an online project from anywhere.

- allow the creation of a virtual identity that can be used as vicarious representations of oneself during these collaborative sessions. This allows a person to share many facets about himself like hobbies, beliefs, ideologies, health information, and the like which contributes to strengthening the virtual relationship.

- facilitate relationships between people, despite differences in culture.

- facilitate the collection of information in a timely manner despite physical barriers.

- facilitate comprehensive learning and allow implementation of concepts acquired globally to a local setting.

\section{Strategy 2: Standards for Inter-operability}

For most developing countries, health information systems are still paperbased. Although there are significant benefits for shifting to electronic reporting formats, mechanisms and capacity to move to this new modality are lacking. This situation, though challenging, offers a unique opportunity for them.

Health informatics standards have been a challenge for the developed world. Because of the readily available technology infrastructure, implementations were created before the need for standards was realized. This resulted in undesirable situations such as having many electronic medical records that are unable to communicate effectively with each other. The lack of standards during the formative period when such were needed to guide implementation is now causing a number of interoperability problems.

The developing world can be spared of this problem if they embrace a common standard early in their implementations. If standards are adopted, the cost of implementation can be brought down significantly and disseminating semantically-consistent health information systems can become possible on a national scale.

To maximize the benefits of standards, developing countries must undergo a process of defining their health needs and designing the enterprise architecture that can respond to them. Guided by this architecture, there can be greater confidence that all information systems complying with it will be able to communicate effectively with each other.

Two important emerging standards for developing countries are the SDMX-HD and the standard geographic codes.

\section{$S D M X-H D$}

SDMX-HD is an abbreviation for Statistical Data and Metadata Exchange (SDMX)-based data exchange format. It is intended to "serve the needs of the Monitoring and Evaluation community." SDMX-HD [14] was developed by WHO and partners to facilitate exchange of indicator definitions and data in aggregate data systems. A simple example of SDMX-HD is to exchange data about number of maternal deaths in a year. Previously, this data would be sent in different formats (as a document, as a spreadsheet or presentation slides) or in varying resolutions (village, to province, to regions) making consolidation and comparisons between countries difficult. SDMX-HD defines the parameters for submitting specific data, its format and semantics, thereby limiting inconsistencies in definition.

\section{National Standards for Geographic Codes}

The health information cycle essentially involves the collection, analysis, presentation and use of health data. Though all these steps are important, presentation of health data deserves special mention because it has the greatest potential to influence decisionmaking by program managers.

One effective method for presenting data is through maps. Due to its intuitive nature, maps are often used to present complex datasets to nontechnical people. This field is called GIS or geographic information systems, and in recent years, it has gained strong support in the heath sector for its simplicity in presenting actionable health information. Contributing to the popularity are the easy availability of software for such as DHIS 2.0 and GoogleMaps.

In order to maximize the benefits of maps however, all health data should be recorded with space and time dimensions. This allows researchers to view health information from chronological and spatial relationships. Standard geographic codes which vary in each country, should be leveraged by health informatics projects in order to be able to present spatially consistent data to decision makers. Only through the use of the same geographic codes can maps about different domains (e.g., dengue or tuberculosis or maternal care) be compared to each other and more complex analysis made possible. 


\section{Strategy 3: Mobile Health - Technology that People Can Understand and Manage}

The last strategy aims to promote the use of mobile phones for health. The growth of mobile phones in Asia and Africa has far exceed that of the developed world [15]. In effect, these regions have leapfrogged over desktops and workstations by going directly to these portable devices. Because of this, there will soon be more people with cellphones in these two regions than there are desktops or laptops in the developed world. Health informatics in the developing world must seriously consider mobile phones in their health informatics implementations. As input devices, cellphones may be limited, but their pervasiveness counters that limitation. Simple text-based reports may be entirely possible with mobile phones [16]. Instead of overly complex data collected on paper, health workers could instead just submit simple data that simply signal the presence of health services in a specific area.

The mobile phone is a unique phenomenon for various reasons. It practically spread out with minimal marketing, without a central authority requiring the purchase except the personal need to communicate. With it, people were able to text or call each other despite the geographic challenges posed by the archipelagos. It also presented an interface that was easy to learn and master. Health informatics for development must investigate the frontiers of mobile phones and their use in health to be able to quantify the value such networks can contribute to better health of the people [17].

\section{Conclusion}

Health informatics requires the presence of both appropriate technology environment and capable human resources to be locally appreciated. The IMIA Working Group on Health Informatics for Development proposes a threepronged strategy to fast-track the inclusion of the developing world into the larger community of health informatics practitioners, to wit: establish partnerships with other networks on health informatics, adopt standards for interoperability, and leverage mobile health as a platform for implementation. Other tools which can be useful are social networks and free/open source software. The availability of international networks such as the Global Health Informatics Partnerships, PANACeA and the like brings these proposed strategies within reach of developing nations and they should take advantage of them to rapidly nurture the field within their countries.

\section{Acknowledgements}

Global Health Informatics Partnerships for the useful insights and references shared by its members in its mailing list.

\section{References}

1. Hersh W. A stimulus to define informatics and health information technology. BMC Med Inform Decis Mak 2009;9:24.

2. Macfarlane SB. Harmonizing health information systems with information systems in other social and economic sectors. Bull World Health Organ 2005 Aug;83(8):590-6.

3. Otero P, Hersh W, Luna D, González Bernaldo de Quirós F. A medical informatics distance-learning course for Latin America. Translation, implementation and evaluation. Methods Inf Med 2010;49(3):310-5.

4. Marin HF, Massad E, Marques EP, Ohno-Machado L. A certificate program in health informatics: Brazil/
USA experience. Stud Health Technol Inform 2006;122:800

5. Margolis A, Verol A, Bessonart L, Barbiel A, Ferla M. Health Information Systems Training for a Countrywide Implementation in Uruguay. Methods Inf Med 2009;2009(1):153-7.

6. Leão BF, Costa CG, Facchini LA, Bandarra EB, Gonçalves SF, Bretas Jr N, et al. The Brazilian health informatics and information policy: building the consensus. Stud Health Technol Inform 2004;107(Pt 2):1207-10.

7. Capurro D. Health informatics in Chile: responding to health reforms. Health Info Libr J 2007 Dec;24(4):287-91.

8. Global Health Informatics Partnership [Internet]. [cited 2011 Jan 31];Available from: http://ghip.net/

9. Rockefeller Foundation Supports Expansion, Training of E-Health Work Force in Developing World | AMIA [Internet]. [cited 2011 Jan 31] Available from: https://www.amia.org/content/ rockefeller-foundation-supports-expansiontrainingof-e-health-work-force-developing-world

10. About PANACeA [Internet]. [cited 2011 Jan 31];Available from: http://panacea-ehealth.net/

11 WHO Geneva University Hospitals - RAFT Network [Internet]. [cited 2011 Apr 21];Available from: http:/ /www.who.int/workforcealliance/members_partners/ member_list/hugraft/en/index.html

12. INDEHELA Programme, University of Kuopio [Internet]. [cited 2011 Apr 21];Available from: http:/ /his.uku.fi/indehela/

13. Curioso WH, Fuller S, Garcia PJ, Holmes KK, Kimball AM. Ten years of international collaboration in biomedical informatics and beyond: the AMAUTA program in Peru. J Am Med Inform Assoc 2010 Aug;17(4):477-80.

14. SDMX-HD (Health Domain) [Internet]. [cited 2011 Apr 21];Available from: http://www.sdmx-hd.org

15.ICT Statistics [Internet]. [cited 2011 Jan 31];Available from: http://www.itu.int//TU-D/ict/ statistics/ict/index.html

16. Mahmud N, Rodriguez J, Nesbit J. A text messagebased intervention to bridge the healthcare communication gap in the rural developing world. Technol Health Care 2010;18(2):137-44.

17. Akter S, Ray P. mHealth - an Ultimate Platform to Serve the Unserved. Yearb Med Inform 2010;;94-100.

\section{Correspondence to:}

Alvin Marcelo

University of the Philippines Manila

National Telehealth Center

Manila, Philippines

Tel: + 6325256501

E-mail: alvin.marcelo@telehealth.ph 